\title{
Histopathological Spectrum of Bone Changes in Skeletal Metastasis
}

\begin{abstract}
Background: Metastatic carcinoma is the most common secondary malignant tumor affecting the bone. Bone is the third most common site for metastasis after lung and liver. The present study was planned to analyze the histomorphological patterns of bone changes in metastatic tumors and their correlation with the radiological findings. Materials and Methods: The current prospective study was conducted over a span of 2 years, encompassing 150 patients with clinically and radiologically suspected metastatic bone disease. Bone biopsy samples were studied for the pattern of bone changes. Results: Of 150 total cases, 30 cases had metastatic bone tumors. The age of the patients ranged from 37 to 84 years (mean: $57.57 \pm 11.9$ years). Male-to-female ratio was 2:1. All patients with metastasis presented with a complaint of pain followed by tenderness $(20,66.7 \%)$. The lesions were commonly located in the vertebral column $(14,46.7 \%)$, followed by femur $(6,20 \%)$. The primary site was known in $21(70 \%)$ cases. The tumor histotypes were adenocarcinoma $(23,76.7 \%)$, squamous cell carcinoma $(5,16.7 \%)$, pleomorphic sarcoma $(1,3.3 \%)$, and malignant melanoma $(1,3.3 \%)$. Histomorphological patterns of bone changes were osteolytic $(16,53.3 \%)$, mixed $(8,26.7 \%)$, and osteoblastic $(6,20.0 \%)$. Correlation between the radiological findings and histopathological patterns of metastases was found to be statistically significant. Conclusions: Histomorphological assessment of bone changes in metastasis is an important parameter. Besides the histological categorization of metastatic bone disease, it plays a pivotal role in identification of the primary tumor site.
\end{abstract}

Keywords: Carcinoma, histomorphological, metastasis, osteoblastic, osteolytic

\section{Introduction}

Tumoral metastasis to the bone is usually a late event in the disease process, wherein the primary tumor site is known in a vast majority. Nevertheless, about 3\%-4\% of the patients with metastasis have an unknown primary tumor at presentation, and of these, approximately $10 \%-15 \%$ have skeletal metastasis. ${ }^{[1]}$ Bone is the third most common site for metastasis after lung and liver, with carcinomatous involvement being predominant. ${ }^{[2]}$ Primaries from breast, prostate, lung, thyroid gland, and kidney have a propensity for metastasis to the bone contributing to more than $80 \%$ of the metastatic tumor load.

Histopathological assessment of bone biopsy material revolves around the tumor diagnosis based on characteristic tumor morphologies and ancillary use of immunohistochemistry in difficult cases. The other aspect which demands consideration is the effect of metastasis on the bone per se. This is constituted by

This is an open access journal, and articles are distributed under the terms of the Creative Commons Attribution-NonCommercial-ShareAlike 4.0 License, which allows others to remix, tweak, and build upon the work non-commercially, as long as appropriate credit is given and the new creations are licensed under the identical terms.

For reprints contact: reprints@medknow.com a plethora of reactive bone destruction and reactive proliferation, which varies from one tumor type to the other, and is seen radiologically as lytic, sclerotic, or mixed lesions. ${ }^{[3]}$ Metastatic bone disease is a diagnostic challenge to the pathologist, given the various modes of presentation and identical histological picture more so when the primary site is unknown. The histomorphological pattern of metastases to the bone is usually selective in terms of site of tumor origin and intraskeletal distribution. A tripartite approach combining clinical, radiological, and pathological information is often conclusive. ${ }^{[4]}$

Literature search reveals the paucity of studies on histomorphological patterns of bone changes in metastatic cancers inspiring us to plan the present study on the subject and a step further to correlate these findings with the radiological picture.

\section{Materials and Methods}

The present prospective study was carried out in the department of pathology, in a tertiary care hospital in collaboration

\footnotetext{
How to cite this article: Baliyan A, Punia RS, Kundu R, Dhingra H, Aggarwal P, Garg SK. Histopathological spectrum of bone changes in skeletal metastasis. Indian J Med Paediatr Oncol 2019;40:476-80.
}

\author{
Asif Baliyan', \\ Rajpal Singh \\ Punia1, \\ Reetu Kundu ${ }^{1}$, \\ Harshi Dhingra ${ }^{1}$, \\ Purnima Aggarwal', \\ Sudhir Kumar Garg ${ }^{3}$ \\ Departments of 'Pathology, \\ ${ }^{2}$ Radiodiagnosis and \\ ${ }^{3}$ Orthopaedics, Government \\ Medical College and Hospital, \\ Chandigarh, India
}

Submitted: 26-Jun-2018 Accepted in Revised Form: 29-Nov-2018

Published: 17-Feb-2020

Address for correspondence: Dr. Reetu Kundu, Department of Pathology, Government Medical College and Hospital, Sector 32-A, Chandigarh - 160 030, India. E-mail: reetukundu@gmail.com

Access this article online

Website: www.ijmpo.org

DOI: 10.4103/ijmpo.ijmpo_142_18 Quick Response Code:

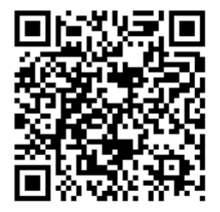


with the departments of orthopedics and radiodiagnosis. The study protocol was approved by the institutional ethics committee, and informed consent was obtained from all the patients. All the 150 patients with clinically and radiologically suspected metastatic bone disease over a period of 2 years (2013-2015) were included in the study. Cases with primary bone tumors, hematolymphoid neoplasms, and patients who had received complete/partial chemotherapy/radiotherapy were excluded from the study.

A detailed history, clinical examination, relevant radiological investigations (X-ray, computed tomography [CT] scan, magnetic resonance imaging [MRI] scan, and bone scan) and clinical diagnoses were recorded from the case files in each case. Bone biopsy from the lesional site was performed in all 150 cases. Biopsy was optimally fixed in $10 \%$ neutral buffered formalin and decalcified using 5\% nitric acid. Routine paraffin embedding was done; sections of 3-5 $\mu \mathrm{m}$ thickness were cut and stained with hematoxylin and eosin stain.

\section{Histopathological assessment}

Histomorphological evaluation was done for the type of metastatic pattern (osteolytic, osteoblastic, mixed, and intertrabecular pattern), neovascularization/angiogenesis, activated mesenchyme/stromal reaction, inflammatory reaction, and associated necrosis. Osteolysis was further divided into very thin trabeculae, lacunar osteolysis, and vanished bone. Osteoblastosis was subdivided into primitive appositional osteoids, osteoid sprouts, and woven bone formation. Mixed pattern comprised features of osteolysis and osteoblastosis. The pattern of bone changes was correlated with the tumor histotype.

A correlation between the clinical, radiological, and final histopathological findings was drawn. Furthermore, an attempt was made to decipher the primary site of metastasis.

\section{Results}

A total of 150 cases suspected for bone involvement were evaluated. Of 150 cases, $30(20 \%)$ cases had metastatic tumor. The age of the patients ranged from 37 to 84 years with the mean of $57.57 \pm 11.9$ years. Male-to-female ratio was $2: 1$.

All patients with metastasis presented with a complaint of pain, followed by tenderness $(20,66.7 \%)$. Less frequent complaints were local swelling and weight loss seen in $2(6.7 \%)$ cases each. The lesions were commonly located in the vertebral column $(14,46.7 \%)$, followed by femur $(6,20 \%)$. Other sites included iliac crest $(4,13.3 \%)$, sacral ala $(2,6.7 \%)$, skull $(1,3.3 \%)$, tibia $(1,3.3 \%)$, phalanx $(1,3.3 \%)$, and humerus $1(3.3 \%)$. Of 30 cases, $21(70 \%)$ cases had known primary sites, which included breast $(7$, $23.3 \%)$, lung $(5,20 \%)$, prostate $(3,10 \%)$, gastrointestinal tract $(2,6.7 \%)$, kidney $(1,3.3 \%)$, skin $(1,3.3 \%)$, soft tissue $(1,3.3 \%)$, and larynx $(1,3.3 \%)$. In the rest of the $9(30 \%)$ cases, the primary site was unknown.

\section{Histomorphological evaluation}

The tumor histotypes in metastatic bone diseases included adenocarcinoma $(23,76.7 \%)$, squamous cell carcinoma $(5,16.7 \%)$, pleomorphic sarcoma $(1,3.3 \%)$, and malignant melanoma $(1,3.3 \%)$. Histomorphological patterns of bone changes in metastasis observed were osteolytic pattern $(16,53.3 \%)$ [Figure 1], mixed $(8,26.7 \%)$, and osteoblastic pattern $(6,20.0 \%)$ [Figure 2]. None of the cases showed intertrabecular pattern. Of $23(76.7 \%)$ cases with metastatic adenocarcinoma, patterns seen were osteolytic in $9(39.1 \%)$, mixed in $8(34.8 \%)$, and osteoblastic in $6(26.1 \%)$ cases. Cases of metastatic squamous cell carcinoma, malignant melanoma, and pleomorphic sarcoma showed only osteolytic pattern. However, this parameter was not statistically significant with $P=0.23$.

Angiogenesis was observed at the tumor margin and between the strands of neoplastic tissue. The capillary proliferation and neoangiogenesis was observed in $21(91.3 \%)$ cases of adenocarcinoma and in all the five cases of squamous cell carcinoma and 1 case of malignant melanoma and pleomorphic sarcoma each. Inflammatory reaction comprising lymphocytes, plasma cells, mast cells, eosinophils, and macrophages along with edema, fibrosis, or necrotic tissue was predominant in margin of metastases, rather than between the foci of neoplastic cells. Inflammatory response was seen in $17(73.9 \%)$ cases of metastatic adenocarcinoma and in all cases of other tumor histotypes. Activated mesenchyme was observed as loose connective tissue consisting of reticular and endothelial cells with large nuclei and containing osteoblasts and sprouting capillaries. It was seen in adenocarcinoma $(21 / 23,91.3 \%)$ and squamous cell carcinoma $(4 / 5,80 \%)$. Necrosis was

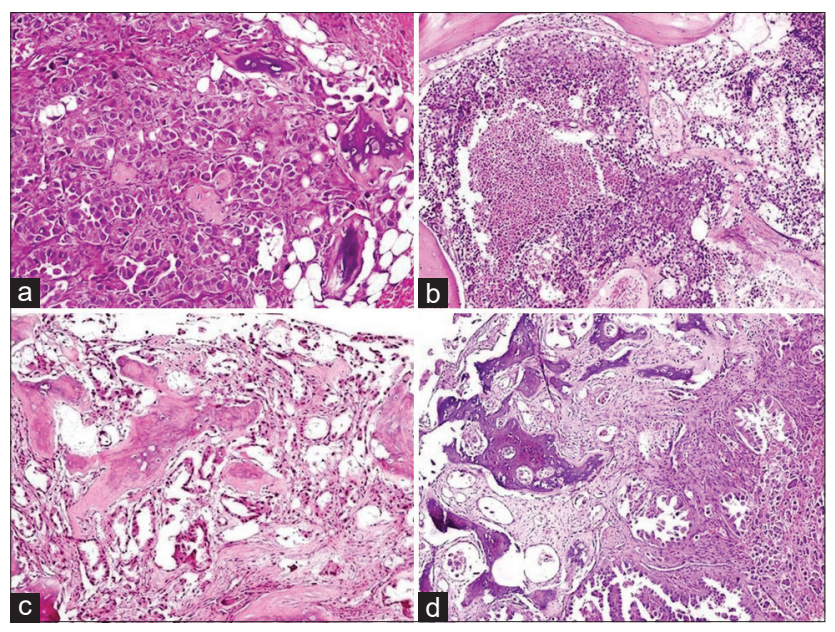

Figure 1: Osteolytic pattern: (a) Vanished bony trabeculae surrounded by tumor cell nests ( $\mathrm{H}$ and $E, \times 200)$. (b) Fragmented bone with necrosis ( $H$ and $E, \times 100)$. (c) Lacunar osteolysis and vanished bone ( $H$ and $E, \times 100)$. (d) Tumor along with fragmented trabeculae of bone $(H$ and $E, \times 100)$ 


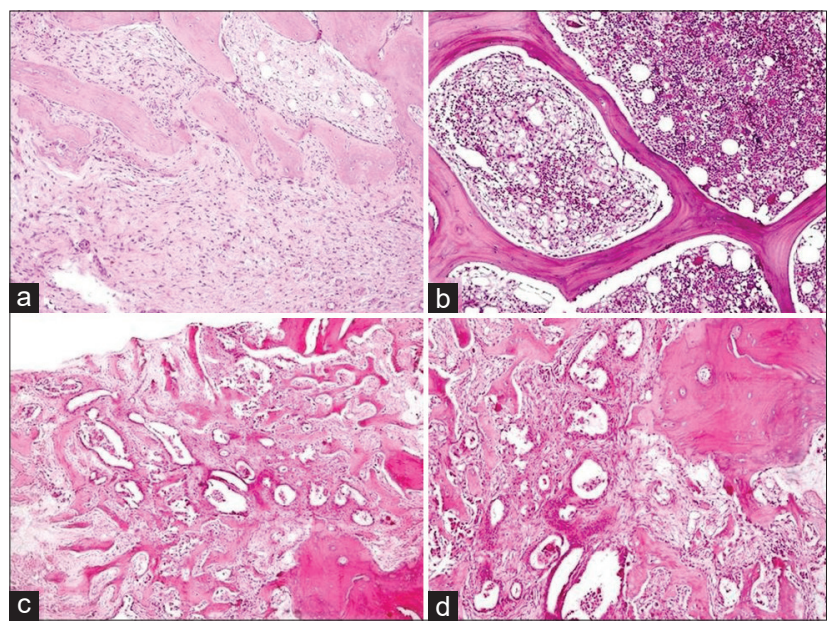

Figure 2: Osteoblastic pattern ( $a$ and $b$ ) and mixed pattern ( $c$ and $d$ ): (a) Osteoid sprouts and appositional osteoids with activated mesenchyme ( $\mathrm{H}$ and $\mathrm{E}, \times 200)$. (b) Bony trabeculae with marrow spaces containing sparse tumor cells ( $H$ and $E, \times 100)$. (c) Osteolysis and osteosclerosis ( $H$ and $E, \times 40)$. (d) Vanished bone and appositional osteoids (H and E, $\times 100$ )

seen frequently in squamous cell carcinoma $(4 / 5,80 \%)$ than adenocarcinoma $(7 / 23,30.4 \%)$.

The relationship between primary site and pattern of metastasis was evaluated in $21 / 30$ cases wherein the primary site was known. Of 7 cases with breast as the primary, osteoblastic $(3,42.9 \%)$, mixed $(3,42.9 \%)$, and osteolytic $(1,14.2 \%)$ patterns were seen. In 3 cases in which primary was in prostate, the patterns observed were osteoblastic $(2,66.7 \%)$ and mixed $(1,33.3 \%)$. In bone metastasis from 11 cases with other known primaries, osteolysis was the lone pattern. This parameter was not statistically significant with $P=0.17$. The expression of carcinomatous osteodysplasia in metastases of unknown primaries (9/30) was predominantly osteolytic (5, 55.6\%), followed by mixed $(3,33.3 \%)$ and osteoblastic $(1,11.1 \%)$ patterns.

\section{Radiological findings}

Radiological findings were osteolytic lesion in 17 (56.7\%) cases, pathological fracture in 7 (23.3\%), mass lesion/space-occupying lesion (SOL) in $3(10 \%)$, mixed lesion in $2(6.7 \%)$, and osteoblastic lesion in $1(3.3 \%)$ case.

\section{Correlation between radiological and histopathological} findings

Radiological findings and histopathological patterns of metastases were compared [Table 1]. Of 17 cases with radiologically detected osteolytic lesions, patterns on histomorphology were osteolytic $(11,64.7 \%)$, mixed (5, 29.4\%), and osteoblastic (1, 5.9\%). Osteosclerotic lesion on radiology in 1 case showed mixed pattern on histopathology. Two cases with mixed lesions on radiology turned out purely with osteoblastic pattern on histopathology. In 7 cases with pathological fracture on radiology, osteolytic 3 (42.9\%), osteoblastic 3 (42.9\%), and mixed $1(14.3 \%)$ patterns were seen on histopathology. Three cases of mass
lesion/SOL seen on radiology showed osteolytic $2(66.7 \%)$ and mixed $1(33.3 \%)$ pattern on histopathology. $P=0.04$ indicates a significant correlation between the radiological and histomorphological parameters.

\section{Discussion}

Distant metastasis in cancer significantly affects the tumor stage, implies a dismal prognosis, and has a therapeutic implication beyond doubt. ${ }^{[5]}$ Metastatic tumors to the skeleton are seen to outnumber the primary bone tumors. ${ }^{[2]}$ Bone marrow is not an uncommon site to be involved by the tumors with hematogenous route of metastasis. The hematopoietic marrow serves as a favorable niche for tumors having predilection for metastasis to the bone. The fact was popularized by Sir Stephan Paget when he proposed the "seed and soil" theory way back in 1889. ${ }^{[6]}$

Skeletal metastases preferentially occur in the axial skeleton: vertebrae, pelvis, ribs, cranium, and the proximal appendicular skeleton. ${ }^{[7,8]}$ Acrometastasis, metastasis distal to the elbow and knee, is rare comprising $<0.1 \%$ of cases..$^{[9,10]}$ Patients may experience pain, pathological fractures, hypercalcemia, bone marrow suppression, spinal cord compression, nerve root compression syndromes, neuromuscular dysfunction, and limited mobility. ${ }^{[3,11]}$ Pain (30/30) was the most common symptomatology observed in the current study.

Bone metastases are classified histologically into osteolytic, osteoblastic, mixed, and intertrabecular types. ${ }^{[12]}$ Carcinomatous osteodysplasia is a term denoting these varied alterations which a cancellous bone undergoes subsequent to involvement of bone marrow by metastatic carcinoma. $^{[13]}$ Osteolytic histological pattern is seen as diffuse osteopenia, thinning of bony trabeculae, destructive bone resorption, lacunar osteolysis, and fragmentation of the bone. Histomorphological features in osteosclerosis are primitive woven bone formed by mineralization of collagenous stroma, appositional new bone formation by osteoblasts on the original trabeculae, and extension of branches of osteoid from the trabecular surface into the central marrow areas seen as sprouts. The mixed type shows an amalgam of features seen in osteoblastic and osteolytic patterns. Diffuse involvement of marrow spaces by tumor cells without affecting the bony trabeculae is peculiar of the intertrabecular pattern. ${ }^{[12]}$

In a large study by Burkhardt et al., ${ }^{[13]} 1164$ bone biopsies were analyzed and metastases were found in 462 cases with tumors from varied primary sites. Carcinomatous osteodysplasia was observed in $91 \%$ cases with mixed pattern being dominant while exclusive osteopenia occurred in $13 \%$ cases only. In a study by Ridell and Landys ${ }^{[14]}$ on bone biopsies from 532 women with unilateral breast cancer, $10 \%$ of cases had metastasis to the bone. Osteolytic (19\%), osteoblastic $(65 \%)$, and unremarkable bone changes $(16 \%)$ 


\begin{tabular}{|c|c|c|c|c|}
\hline Parameter & Adenocarcinoma (23) & $\begin{array}{l}\text { Squamous cell } \\
\text { carcinoma (5) }\end{array}$ & $\begin{array}{l}\text { Malignant } \\
\text { melanoma (1) }\end{array}$ & $\begin{array}{l}\text { Pleomorphic } \\
\text { sarcoma (1) }\end{array}$ \\
\hline Metastatic site (30) & $\begin{array}{l}\text { Vertebrae (12), femur (4), iliac crest (3), } \\
\text { humerus (1), sacrum (1), phalanx (1) }\end{array}$ & $\begin{array}{l}\text { Femur (2), } \\
\text { vertebrae (2), tibia (1) }\end{array}$ & Skull (1) & Iliac crest (1) \\
\hline Primary site (21) & $\begin{array}{l}\text { Breast (7), prostate (3), lung (2), GIT (2), } \\
\text { kidney (1), unknown (8) }\end{array}$ & $\begin{array}{l}\text { Lung (3), larynx (1), } \\
\text { unknown (1) }\end{array}$ & Facial skin (1) & $\begin{array}{l}\text { Soft tissue, lower } \\
\text { extremity (1) }\end{array}$ \\
\hline Osteolytic pattern (16) & $\begin{array}{l}\text { Vanished bone (7), very thin trabeculae } \\
\text { (5), lacunar osteolysis (2) }\end{array}$ & $\begin{array}{l}\text { Vanished bone (4), very } \\
\text { thin trabeculae (3), } \\
\text { lacunar osteolysis (1) }\end{array}$ & $\begin{array}{l}\text { Vanished bone } \\
\text { and very thin } \\
\text { trabeculae (1) }\end{array}$ & $\begin{array}{l}\text { Vanished bone and } \\
\text { lacunar osteolysis } \\
\text { (1) }\end{array}$ \\
\hline Osteoblastic pattern (6) & $\begin{array}{l}\text { Appositional osteoid (6), } \\
\text { osteoid sprouts ( } 3 \text { ) }\end{array}$ & None & None & None \\
\hline Mixed pattern (8) & $\begin{array}{l}\text { Appositional osteoid ( } 8) \text {, } \\
\text { vanished bone ( } 7) \text {, very thin trabeculae } \\
(1), \text { osteoid sprouts (1) }\end{array}$ & None & None & None \\
\hline Osteoclasts (21) & 16 & 4 & 1 & None \\
\hline Osteoblasts (23) & 18 & 4 & None & 1 \\
\hline Capillary proliferation (28) & 21 & 5 & 1 & 1 \\
\hline Activated mesenchyme (26) & 21 & 4 & 1 & None \\
\hline Inflammatory response (24) & 17 & 5 & 1 & 1 \\
\hline \multirow[t]{2}{*}{ Necrosis (12) } & 7 & 4 & None & 1 \\
\hline & Histomorphological patterns & & & \\
\hline \multicolumn{5}{|l|}{ Radiological lesions } \\
\hline Osteolytic (17) & Osteolytic (7), osteoblastic (1), mixed (5) & Osteolytic (3) & None & Osteolytic (1) \\
\hline Osteosclerotic (1) & Mixed (1) & None & None & None \\
\hline Osteolytic and osteosclerotic (2) & Osteoblastic (2) & None & None & None \\
\hline Pathological fracture (7) & Osteoblastic (3), osteolytic (2), mixed (1) & Osteolytic (1) & None & None \\
\hline Mass lesion/SOL (3) & Mixed (1) & Osteolytic (1) & Osteolytic (1) & None \\
\hline
\end{tabular}

SOL - Space-occupying lesion

were noted. In the present study, histomorphological patterns of bone changes were osteolytic (16, 53.3\%), mixed $(8,26.7 \%)$, and osteoblastic $(6,20.0 \%)$.

Mechanisms causing varied histomorphological bone patterns in metastasis are of complex nature and not precisely understood. ${ }^{[15-20]}$ Osteolytic metastasis occurs in primaries from breast, thyroid, lung, and kidney. Tumor cells produce chemokine receptors 4, cell adhesion molecules ( $\alpha 4 \beta 1$ or $\alpha 2 \beta 1$ integrins), and cell surface receptors causing osteoclast stimulation. Bone resorption releases growth factors: transforming growth factor $\beta$ (TGF $\beta)$, fibroblastic growth factor (FGF), insulin-like growth factor, and bone morphogenetic protein (BMP)-2, which stimulate the production and release of bone resorbing factors from tumor cells. TGF $\beta$ stimulates parathyroid hormone-related protein inducing the expression of receptor activator of nuclear factor kappa B ligand (RANKL) on bone marrow stromal cells. RANKL binds the RANK receptor on osteoclast precursors generating mature osteoclasts. There is enough evidence supporting endothelin-1, TGF $\beta$, FGF, proteases, and BMPs as the key mediators of osteoblastic metastasis seen in primaries from prostate, colon, brain, and cervix.

Radiology furnishes diagnostic information providing valuable inputs to the pathologist in skeletal metastasis. Plain radiograph as an initial imaging modality suffers from poor sensitivity as more than $50 \%-70 \%$ of bone destruction should occur for a reliable detection. ${ }^{[21,22]}$ CT scans, MRI, positron emission tomography scans, scintigraphy, and hybrid imaging techniques possess better sensitivity. ${ }^{[3,23]}$ In a study on radiographic appearances in bone metastasis from carcinoma breast, lytic lesions were seen in 72 cases, sclerotic in 37, and mixed in 33 cases out of 142 cases where bone lesions were visualized. ${ }^{[24]}$ In the current study, osteolytic lesions $(17,56.7 \%)$, pathological fractures (7, 23.3\%), mass lesions/SOLs (3, 10\%), mixed lesions (2, 6.7\%), and osteoblastic lesion $(1,3.3 \%)$ were seen. The correlation between radiological and histopathological findings was good.

\section{Conclusions}

Careful histomorphological assessment in metastasis to the bone is virtually essential for an accurate diagnosis and in identifying the possible primary site in cases with unknown primaries. Radiological findings and immunohistochemistry are useful resources in challenging cases. Furthermore, the histopathological bone patterns may help in planning appropriate palliative therapy in these patients.

\section{Financial support and sponsorship}

Nil. 


\section{Conflicts of interest}

There are no conflicts of interest.

\section{References}

1. Rougraff BT. Evaluation of the patient with carcinoma of unknown origin metastatic to bone. Clin Orthop Relat Res 2003;415:S105-9.

2. Mundy GR. Metastasis to bone: Causes, consequences and therapeutic opportunities. Nat Rev Cancer 2002;2:584-93.

3. O’Sullivan GJ, Carty FL, Cronin CG. Imaging of bone metastasis: An update. World J Radiol 2015;7:202-11.

4. Salmon JM, Kilpatrick SE. Pathology of skeletal metastases. Orthop Clin North Am 2000;31:537-44, vii-viii.

5. Disibio G, French SW. Metastatic patterns of cancers: Results from a large autopsy study. Arch Pathol Lab Med 2008;132:931-9.

6. Fidler IJ, Poste G. The "seed and soil" hypothesis revisited. Lancet Oncol 2008;9:808.

7. Kakhki VR, Anvari K, Sadeghi R, Mahmoudian AS, Torabian-Kakhki M. Pattern and distribution of bone metastases in common malignant tumors. Nucl Med Rev Cent East Eur 2013;16:66-9.

8. Virk MS, Lieberman JR. Tumor metastasis to bone. Arthritis Res Ther 2007;9 Suppl 1:S5.

9. Stomeo D, Tulli A, Ziranu A, Perisano C, De Santis V, Maccauro G, et al. Acrometastasis: A literature review. Eur Rev Med Pharmacol Sci 2015;19:2906-15.

10. Piccioli A, Maccauro G, Spinelli MS, Biagini R, Rossi B. Bone metastases of unknown origin: Epidemiology and principles of management. J Orthop Traumatol 2015;16:81-6.

11. Coleman RE. Clinical features of metastatic bone disease and risk of skeletal morbidity. Clin Cancer Res 2006;12:6243s-9s.

12. Vukmirovic-Popovic S, Colterjohn N, Lhoták S, Duivenvoorden WC, Orr FW, Singh G. Morphological, histomorphometric, and microstructural alterations in human bone metastasis from breast carcinoma. Bone 2002;31:529-35.

13. Burkhardt R, Frisch B, Schlag R, Sommerfeld W. Carcinomatous osteodysplasia. Skeletal Radiol 1982;8:169-78.

14. Ridell B, Landys K. Incidence and histopathology of metastases of mammary carcinoma in biopsies from the posterior iliac crest. Cancer 1979;44:1782-8.

15. Chappard D, Bouvard B, Baslé MF, Legrand E, Audran M. Bone metastasis: Histological changes and pathophysiological mechanisms in osteolytic or osteosclerotic localizations. A review. Morphologie 2011;95:65-75.

16. Roodman GD. Mechanisms of bone metastasis. N Engl J Med 2004;350:1655-64.

17. Macedo F, Ladeira K, Pinho F, Saraiva N, Bonito N, Pinto L, et al. Bone metastases: An overview. Oncol Rev 2017;11:321.

18. Yin JJ, Pollock CB, Kelly K. Mechanisms of cancer metastasis to the bone. Cell Res 2005;15:57-62.

19. Coleman RE. Metastatic bone disease: Clinical features, pathophysiology and treatment strategies. Cancer Treat Rev 2001;27:165-76.

20. Keller ET, Zhang J, Cooper CR, Smith PC, McCauley LK, Pienta KJ, et al. Prostate carcinoma skeletal metastases: Cross-talk between tumor and bone. Cancer Metastasis Rev 2001;20:333-49.

21. Cuccurullo V, Cascini GL, Tamburrini O, Rotondo A, Mansi L. Bone metastases radiopharmaceuticals: An overview. Curr Radiopharm 2013;6:41-7.

22. Choi J, Raghavan M. Diagnostic imaging and image-guided therapy of skeletal metastases. Cancer Control 2012;19:102-12.

23. Messiou C, Cook G, deSouza NM. Imaging metastatic bone disease from carcinoma of the prostate. $\mathrm{Br} \mathrm{J}$ Cancer 2009;101:1225-32.

24. James JJ, Evans AJ, Pinder SE, Gutteridge E, Cheung KL, Chan $\mathrm{S}$, et al. Bone metastases from breast carcinoma: Histopathological-radiological correlations and prognostic features. Br J Cancer 2003;89:660-5. 